\title{
POLÍTICA PÚBLICA DE ASSISTÊNCIA ESTUDANTIL NO ENSINO SUPERIOR: O PROGRAMA BOLSA PERMANÊNCIA NA UNIVERSIDADE FEDERAL DA GRANDE DOURADOS
}

\author{
POLÍTICA PÚBLICA DE ASISTENCIA AL ESTUDIANTE EN LA ENSEÑANZA \\ SUPERIOR: EL PROGRAMA BECA DE PERMANENCIA EN LA UNIVERSIDAD \\ FEDERAL DE GRANDE DOURADOS
}

\begin{abstract}
PUBLIC POLICY ON STUDENT ASSISTANCE IN HIGHER EDUCATION: THE PERMANENCY SCHOLARSHIP PROGRAM AT THE FEDERAL UNIVERSITY OF GRANDE DOURADOS
\end{abstract}

\author{
Adriana Carla Teixeira da Costa BRITO ${ }^{1}$ \\ Kellcia Rezende SOUZA ${ }^{2}$ \\ Vera Luci de ALMEIDA ${ }^{3}$
}

RESUMO: Este trabalho tem por objetivo fazer um diagnóstico da gestão de planejamento e utilização do aporte financeiro concedido ao programa bolsa permanência da Universidade Federal da Grande Dourados (UFGD). Nesse sentido, procurar-se-á evidenciar como é feita a distribuição do recurso a fim de garantir o direito da assistência estudantil na instituição. A metodologia empregou a pesquisa qualitativa, com intuito de obter uma análise profunda do benefício dentro do contexto institucional da UFGD e, para isso, foram utilizados dados documentais para a construção do panorama gerencial da concessão de bolsas do programa bolsa permanência da UFGD. A assistência estudantil é potencialmente estratégica para democratização do acesso e permanência dos estudantes da UFGD, entretanto, o resultado da pesquisa culminou em sobra de recursos, o que poderia ser diagnosticado e corrigido pela gestão, caso houvesse o monitoramento e a avaliação das ações.

PALAVRAS-CHAVE: Ensino Superior. Política pública de assistência estudantil. Programa de Bolsa Permanência.

RESUMEN: Este trabajo tiene como objetivo hacer un diagnóstico de la gestión de la planificación y el uso de la contribución financiera otorgada al programa de becas de la Universidad Federal de Grande Dourados (UFGD). En este sentido, trataremos de mostrar cómo se distribuye el recurso para garantizar el derecho de asistencia estudiantil en la institución. La metodología utilizó investigación cualitativa, para obtener un análisis

\footnotetext{
${ }^{1}$ Universidade Federal da Grande Dourados (UFGD), Dourados - MS - Brasil. Doutoranda no Programa de Pós-Graduação em Educação. Assistente em Administração da UFGD - Dourados (COGRAD/PROGRAD). ORCID: https://orcid.org/0000-0002-3356-0456. E-mail: adrianacarlacosta@gmail.com

${ }^{2}$ Universidade Federal da Grande Dourados (UFGD), Dourados - MS - Brasil. Professora Adjunta atuando no Programa de Pós-Graduação em Educação e no Programa de Pós-Graduação em Administração Pública. Doutorado em Educação Escolar (UNESP). ORCID: https://orcid.org/0000-0002-8663-4615. E-mail: kellcia@hotmail.com

${ }^{3}$ Universidade Federal da Grande Dourados (UFGD), Dourados - MS - Brasil. Docente Associada. Doutorado em Engenharia e Gestão do Conhecimento (UFSC). ORCID: https://orcid.org/0000-0003-1020-9169. E-mail: vera.vla@gmail.com
}

RIAEE - Revista Ibero-Americana de Estudos em Educação, Araraquara, v. 16, n. 2, p. 508-523, abr./jun. 2021. e-ISSN: 1982-5587 DOI: https://doi.org/10.21723/riaee.v16i2.13671 
profundo del beneficio dentro del contexto institucional de UFGD y, para ello, se utilizaron datos documentales para construir el panorama gerencial de la concesión de becas del programa de becas UFGD. La asistencia estudiantil es potencialmente estratégica para la democratización del acceso y la permanencia de los estudiantes de UFGD, sin embargo, el resultado de la investigación culminó en recursos excedentes, que podrían ser diagnosticados y corregidos por la administración, si las acciones fueran monitoreadas y evaluadas.

PALABRAS CLAVE: Educación Universitaria. Política pública de asistencia al alumno. Programa de Becas de Permanencia.

ABSTRACT: This work aims to make a diagnosis of the planning management and the use of the financial contribution granted to the scholarship program of the Federal University of Grande Dourados (UFGD). In this sense, we will try to show how the resource is distributed to guarantee the right of student attendance in the institution. The methodology used qualitative research to obtain an in-depth analysis of the benefit within the institutional context of UFGD and, for this, documentary data was used to construct the management panorama of the scholarship award of the UFGD scholarship program. Student assistance is potentially strategic for the democratization of access and permanence of UFGD students, however, the result of the investigation culminated in surplus resources, which could be diagnosed and corrected by the administration, if the actions were monitored and evaluated.

KEYWORDS: Higher Education. Public policy of student assistance. Permanence Scholarship Program.

\section{Introdução}

A assistência estudantil toma lugar na agenda de políticas públicas a partir da Constituição Federal de 1988 (momento que ficou reconhecida educação como um direito social), da Lei de Diretrizes e Bases de 1996 (em que estabeleceu as diretrizes para diferentes níveis de educação e também explicitou aspectos relacionados à assistência dos estudantes), e do Programa Nacional de Assistência Estudantil - PNAES, instituído pelo Ministério da Educação, por meio da Normativa $n^{\circ} 39 / 2007$ e do Decreto $n^{\circ} 7.234 / 2010$, (trata-se do marco histórico para a política de assistência estudantil por sua efetiva articulação com as atividades de ensino, pesquisa e extensão, com foco na permanência dos estudantes nos cursos de graduação).

Ainda com ações incipientes, no ano de 2007, a Universidade Federal da Grande Dourados (UFGD) deu início as atividades de assistência estudantil, concedendo, naquele momento, trinta bolsas permanência e assim por diante, ofertando já em 2017, o quantitativo de 1.543 bolsas aos estudantes perfis da universidade. O PNAES prevê a execução de monitoramento e avaliação das ações, no inciso II, do artigo $5^{\circ}$, e a UFGD não possui 
qualquer forma de monitoramento do programa. Esta contextualização remete à seguinte questão: Como estabelecer o monitoramento e a avaliação do Programa Bolsa Permanência da UFGD?

Justifica-se a pesquisa, pois para Secchi (2010), a etapa de monitoramento tem a finalidade de verificar o cumprimento das ordenações e de corrigir eventuais falhas. Esta avaliação pretende averiguar se as metas, os objetivos, a eficiência, a eficácia e a efetividade da política foram alcançados. Para a efetiva avaliação do programa optou-se por construir o panorama de utilização do recurso Programa Bolsa Permanência da UFGD, entre os anos de 2014 a 2017 devido à insuficiência de dados nos demais anos.

Para a realização dessa pesquisa, mediante abordagem qualitativa, foi realizada pesquisa bibliográfica e documental. O corpus da pesquisa foi construído pelo cruzamento de dados da Pró-reitora de Assuntos Comunitários e Estudantis (PROAE) e da Pró-reitora de Graduação (PROGRAD), dentre os documentos, podemos destacar: Relatórios de Gestão, Relatório de Auditoria, Relatório de Avaliação dos Resultados da Gestão, Atos Administrativos (Instruções de Serviços, Editais e Resoluções) e, principalmente, procurou-se respaldo na busca de Regulamentos próprios do Programa Bolsa Permanência da UFGD.

\section{Política Pública de Assistência Estudantil}

Os programas de assistência estudantil na educação superior brasileira existem desde o surgimento das primeiras universidades na década de 1920, embora de forma pontual e fragmentada. Tais programas de assistência passaram a assumir formas mais democráticas somente a partir da Constituição Federal de 1988. É a partir de então que esses programas introduziram novas perspectivas, as quais tornaram suas ações mais abrangentes, para além dos auxílios monetários ou de acompanhamento das trajetórias de vida pessoal e acadêmicas dos estudantes, com apoio psicológico e infraestrutura adequada.

De acordo com a Constituição Federal de 1988, a educação é direito fundamental, universal e inalienável, instrumento de formação da cidadania e meio de emancipação social (BRASIL, 1988, Art. 205). O conceito de educação pública nasce na Europa do século XVI, concomitante à consolidação da ideia de Estado-Nação, o que fez da educação um instrumento de ação política e de interesse do Estado, conforme discute Ranieri (2009). Nessa perspectiva, a autora coloca que seria possível a utilização da educação como um instrumento de luta por direitos humanos e de cidadania.

RIAEE - Revista Ibero-Americana de Estudos em Educação, Araraquara, v. 16, n. 2, p. 508-523, abr./jun. 2021. e-ISSN: 1982-5587 
A história da educação brasileira e, em particular, a história de expansão da educação superior nacional, não foi diferente. Entre as principais características desse processo que ocorreu na década de 1930, segundo Ristoff (2008), está no destaque para a multiplicação de escolas, em detrimento da ampliação daquelas já existentes. Essa demanda foi altamente explorada pela nova classe média urbana em formação, denominada burguesa. Inicialmente, a burguesia exigia para si uma ampliação do ensino público secundário e a partir de então, passou a pressionar o poder público para a criação do nível subsequente, o superior.

Então, é a partir desse contexto da década de 1930 que ocorre a Primeira Reforma no Ensino Superior. Conforme Finatti, Alves e Silveira (2007), essa Reforma previa a normatização da educação superior no país, a fim de atender à crescente demanda por novos cursos e o aumento de vagas nas universidades. Diante disso, Romanelli (2009, p. 109) discute que esse período ficou marcado por uma educação que oscilava entre atender os interesses das camadas populares, representadas pela ascendente burguesia, que clamavam por mais educação e aos interesses das classes dominantes, representadas pela oligarquia cafeeira, que tentavam conter as pressões dessas camadas. Após o golpe de 1964, permanecia entre estudantes e professores um clima de insatisfação com a estrutura universitária existente. Em várias instituições, alunos e professores realizaram "cursos paralelos", com vistas a expressar a sua discordância com relação aos currículos existentes (MARTINS, 2009). A Reforma de 1968, segundo Martins (2009), produziu efeitos paradoxais no ensino superior brasileiro, uma vez que possibilitou a modernização de parte significativa das universidades federais, além de determinadas instituições estaduais e confessionais, que incorporaram gradualmente as modificações acadêmicas propostas pela Reforma.

$\mathrm{Na}$ década de 1980, segundo Martins (2009), em função da crise econômica vivenciada pelo país, expressa em um grave quadro inflacionário e no aumento das taxas de desemprego, ocorreu uma desaceleração da expansão do ensino superior. Nesse momento, as instituições públicas passaram a se instalar em áreas geográficas de menor interesse econômico para a rede privada.

Na sequência cronológica dos fatos históricos sobre a educação superior brasileira e o florescer de uma política de assistência educacional, há de se destacar ainda a década de 1990 . Segundo Chauí (2001), a economia nacional dos anos de 1990, durante o governo de Fernando Henrique Cardoso (FHC), sofreu ajustes neoliberais. Isto significou, entre outras coisas, a adoção de medidas de privatização de empresas do Estado com vistas a equilibrar o valor da nova moeda em vigência no Brasil, o Real. Esse foco na economia acabou por influenciar as políticas educacionais desse período. 
Dessa forma, as universidades passaram a tomar como perspectiva a preparação de sujeitos para o mercado de trabalho. Houve, assim, um forte incentivo à racionalidade e à eficiência no ensino superior. É também nesse momento que as políticas educacionais se voltam para a privatização do ensino, de modo a viabilizar uma maior abertura desse campo para as universidades particulares, enquanto consequência de uma acomodação do capitalismo brasileiro, conforme discutem Mancebo, Vale e Martins (2015).

Por conseguinte, no início dos anos 2000, as políticas educacionais passaram a imprimir uma identidade fortemente marcada pela democratização do acesso e permanência ao ensino superior, através da adoção de diferentes medidas que buscavam oportunizar o acesso à educação às camadas sociais de baixa renda. Assim, em 2007, guiando-nos por Martins (2009), durante o governo de Luís Inácio Lula da Silva, foi instituído o Programa de Apoio aos Planos de Reestruturação e Expansão das Universidades Federais, o REUNI, com a finalidade de fornecer às universidades subsídios necessários à ampliação do acesso de pessoas aos seus cursos; bem como, o REUNI foi criado com o objetivo de aumentar a qualidade dos cursos oferecidos pelas instituições públicas de ensino; além de prever a melhoria das estruturas físicas das universidades e a revisão das estruturas curriculares acadêmicas.

Andrés (2011) observa que no primeiro relatório do REUNI há, além da criação de novas vagas, a proposta das Instituições Federais de Ensino Superior (Ifes) para a criação de ações direcionadas ao preenchimento de vagas ociosas, oriundas da significativa evasão de acadêmicos por elas observadas. Segundo Gaioso (2005, p. 98), a evasão escolar pode ser entendida como uma “[...] interrupção no ciclo de estudos [...]" provocada por qualquer motivo. O desligamento costuma ser maior nos anos iniciais do curso (RIBEIRO, 2005) - e nele, a saída tende a ser maior nos primeiros três meses. Conforme dados levantados, o primeiro ano do REUNI apontou um crescimento acentuado das matrículas projetadas nos cursos de graduação: a previsão inicial era de um aumento de $10 \%$ em relação a 2007, que totalizava 645.638 matrículas projetadas - meta ligeiramente superada, dado o resultado no final de 2008, de 715.185 matrículas (que equivale a $10,77 \%$ a mais de matriculados previstos).

Também no ano de 2007 foi instituído, em âmbito federal, o Programa Nacional de Assistência Estudantil (PNAES), por meio da Portaria Normativa ${ }^{\circ}{ }^{\circ}$ 39, de 12 de dezembro de 2007; para os estudantes de cursos de graduação presenciais das Ifes, sendo implementado a partir do ano de 2008. Trata-se de um marco histórico para a política de assistência por definir 
suas áreas de ação, como também por ser um referencial para os programas e projetos realizados nas diversas universidades do Brasil.

Dessa forma, logo essas discussões sobre a política de assistência estudantil tomaram lugar na agenda dos movimentos estudantis e foram acolhidas pelos movimentos sociais no Fórum Nacional de Pró-Reitores de Assuntos Comunitários e Estudantis (FONAPRACE), levando gestores a refletirem sobre a formulação e a implementação de políticas sociais que viessem a favorecer a permanência dos estudantes nas universidades (FONAPRACE, 2012).

Nesse sentido, é a partir do PNAES que a assistência estudantil se efetiva na articulação com atividades de ensino, pesquisa e extensão, tendo como foco principal a permanência dos estudantes nos seus cursos de graduação. Segundo Imperatori (2017), a proposta do PNAES é articular diferentes áreas e, consequentemente, diferentes políticas sociais, com o intuito de garantir um padrão de proteção social amplo. Tal programa também é responsável por possibilitar a garantia de recursos específicos às Ifes, com a finalidade de implementar ações de assistência estudantil, as quais, por conseguinte, passaram a ser entendidas como parte da política educacional, cujo objetivo é fornecer os recursos necessários para que os estudantes ultrapassem os obstáculos ao bom desempenho acadêmico.

Diante do exposto, torna-se possível observar que embora já tivessem universidades federais públicas com gratuidade do ensino no Brasil, é somente com a implantação do REUNI e do PNAES que o acesso à educação superior se tornou possível para os filhos da classe trabalhadora, visto que a permanência na universidade requer o atendimento de necessidades sociais objetivas destes estudantes ingressantes (isto é, transporte, alimentação, material didático e etc.). Ou seja, a educação superior precisa também ser compreendida enquanto uma "expressão da questão social", cuja desigualdade de acesso, permanência e qualidade residem no fato de serem produzidas e reproduzidas historicamente, a partir das condições econômicas, políticas e sociais impostas pelo capital (MACHADO, 2013).

Para Imperatori (2017), com o incentivo de tais políticas públicas, as matrículas na educação superior brasileira cresceram de 3,9 milhões em 2003 para 7,3 milhões em 2013 - o equivalente a 86\%. O contingente de estudantes matriculados na educação superior em 2013 representa uma taxa de escolarização bruta de $29 \%$ e taxa de escolarização líquida, de $18 \%$. Já no ano de 2016, segundo dados do Censo da Educação Superior, foram ofertadas 10.662.501 vagas no Ensino Superior e, destas, 19.302 vagas foram destinadas aos Programas especiais de reestruturação.

Assim sendo, Fernandes (2015) afirma que essas novas tendências à democratização de acesso ao ensino superior gerou a longo prazo um forte impacto sobre as Ifes, tanto 
públicas quanto privadas, uma vez que elas deveriam estar preparadas para receber alunos provenientes de outras regiões e, por isso, com costumes, culturas, condições socioeconômicas e bases educacionais diferentes entre si. Eis o novo desafio ao qual as universidades devem estar atentas para que, de fato, consiga potencializar os seus objetivos de formar cidadãos conscientes e bem preparados para ingressar no mercado de trabalho.

\section{Avaliação do Programa Bolsa Permanência na UFGD}

Esse estudo priorizou a investigação do Programa Bolsa Permanência da UFGD por se tratar de um dos programas que utiliza grande aporte financeiro advindo dos recursos do PNAES e por estar diretamente ligado à permanência e à manutenção do estudante na universidade.

Segundo Sousa (2006), para a construção e o fortalecimento de políticas públicas, fazse necessário considerar o tipo de problema que a política visa corrigir, além de observar como este problema chega a essa esfera e quais instituições irão definir, modelar e implementá-la. As fases de implementação e execução são consideradas pelos especialistas da área como as mais complexas. De tal forma, para Secchi (2010), as Políticas Públicas, por ocorrerem em ambientes de alta densidade política e entre atores do Estado e da sociedade, devem ser formuladas a partir de ciclo.

O processo de elaboração de políticas públicas, ou ciclo de políticas públicas, pode ser entendido como um esquema a partir de estágios sequenciais e interdependentes que explicam a sua vida (SECCHI, 2010). Rua (2009) afirma que essas etapas que compõem um processo de elaboração dessas políticas são compreendidas não como uma ação linear, mas como uma unidade contraditória, em que o ponto de partida não está claramente definido e as atividades de etapas distintas podem ocorrer simultaneamente.

Por sua vez, o monitoramento desse processo consiste no acompanhamento da implementação de uma política, com a finalidade de verificar o cumprimento das ordenações e de corrigir eventuais falhas. A avaliação que é feita durante o monitoramento visa averiguar se as metas, os objetivos, a eficiência, a eficácia e a efetividade da política foram alcançados. Esta fase é considerada primordial, pois é capaz de garantir o sucesso da política, uma vez que os resultados e impactos são verificados nela. Logo, para que o monitoramento e a avaliação sejam efetivos, é necessário que eles estejam previstos no desenho da política, inclusive com os seus instrumentos (CONDÉ, 2013). Arretche (2009) diferencia "análise de políticas públicas" de "avaliação de políticas públicas". De acordo com a autora, a análise de políticas 
públicas está relacionada ao desenho institucional de uma política pública, ao arranjo segundo o qual uma política foi formulada e implementada.

É, nesse sentido, que intensifica a necessidade do monitoramento do Programa Bolsa Permanência da UFGD, o qual consiste em fornecer um incentivo pecuniário no valor de R\$ 400,00, recebido mensalmente pelos estudantes de graduação em situação de vulnerabilidade socioeconômica. Trata-se de uma política de assistência que tem por finalidade estabelecer um apoio financeiro com vistas a garantir a permanência do aluno que esteja regularmente matriculado em cursos presenciais de graduação na Instituição.

Este programa está normatizado através da Resolução COUNI n 2019, de 27 de novembro de 2017, que aprova o regulamento do Programa Bolsa Permanência e a Resolução $\mathrm{n}^{\mathrm{o}} 35$, de 11 de março de 2015, que define o processo de avaliação socioeconômica dos alunos.

O Programa Bolsa Permanência consiste na abertura de editais disponíveis a toda comunidade e para participação o aluno tem que cumprir cumulativamente as seguintes condições:

a) Realizar a Avaliação Socioeconômica e ser classificado no Perfil I ${ }^{4}$.

b) Estar regularmente matriculado com carga horária mínima de 432 horas/aula no semestre para os cursos integrais de graduação e carga horária mínima de 288 horas/aula no semestre para os demais cursos presenciais de graduação da UFGD.

c) Estar regularmente matriculado com carga horária mínima de 432 horas/aula no semestre para os casos de complementação de habilitação ou grau, para cursos de graduação integral, concluídos anteriormente.

d) Estar regularmente matriculado com carga horária mínima de 288 horas/aula no semestre para os casos de complementação de habilitação ou grau, para cursos de graduação não integral, concluídos anteriormente.

e) Estar regularmente matriculado, ou já ter cursado anteriormente, todas as disciplinas obrigatórias do semestre e estar matriculado nas disciplinas de redação de dissertação ou tese, ou equivalentes, para os cursos de Mestrado e Doutorado da UFGD.

f) Não ser beneficiário de outras modalidades de bolsas oferecidas pela UFGD e/ou outras instituições que não autorizem a acumulação de benefícios. Para fins de Assistência Estudantil, a bolsa permanência é acumulável com outros benefícios de assistência estudantil e programas de bolsas de ensino, pesquisa, extensão e cultura.

g) Não estar matriculado em cursos presenciais de graduação da UFGD com carga horária média superior ou igual a cinco horas/aulas diárias (UFGD, 2017).

${ }^{4} \mathrm{O}$ estudante que comprove, através do processo de Avaliação Socioeconômica, possuir renda familiar per capita de até 1,5 salários mensais. 
A inscrição do aluno é realizada pelo Sistema Acadêmico e a ordem de classificação dos estudantes é determinada pelo índice de classificação (IC) que se refere à condição de vulnerabilidade do estudante. Essa classificação é ordenada de forma decrescente, sendo a ordem disposta do maior para o menor grau de vulnerabilidade. A homologação da classificação não garante o recebimento da bolsa, de tal forma que, o aluno deve entregar na PROAE o termo de compromisso devidamente assinado, para, assim, efetivar a concessão do direito a bolsa. Até o ano de 2015, o Regulamento do Programa Bolsa Permanência previa que o estudante bolsista desenvolvesse atividades em projetos sociais, projetos de pesquisa, de ensino, de extensão, ou ainda, que participasse do programa de apoio pedagógico de Língua Portuguesa, Língua Estrangeira, Matemática e Informática da Pró-reitora de Assuntos Comunitários e Estudantis (PROAE), de forma a cumprir uma carga horária mínima de 20 horas mensais. Entretanto, em 2015 os gestores passaram a entender que a política de assistência estudantil não deveria estar atrelada a qualquer outra atividade. Isto significa dizer que, conforme a nova compreensão dessa política, o aluno bolsista deveria receber a bolsa apenas para a sua manutenção no ensino superior.

A UFGD iniciou suas atividades com a Política de Assistência Estudantil, através do PNAES, em 2006. Assim, de 2007 a 2017 foram previstos para a instituição em torno de R\$ 43.000.000,00 (quarenta e três milhões de reais), alocados no Programa 2080 da Educação Superior, sob a rubrica 4002, com destino à Assistência Estudantil.

Para a gestão do recurso, a legislação que rege o PNAES permite que as universidades planejem e distribuam o orçamento entre as ações do Programa, prevendo, entretanto, a aplicação com base nos objetivos e nas áreas passíveis de atuação dispostas no Decreto 7.234/2010. Dessa forma, a Figura 1 apresenta os recursos previstos e pagos pela UFGD entre os anos de 2007 a 2017.

Figura 1 - Recursos autorizados, pagos e restos a pagar da UFGD do Programa 2080Educação Superior, sob o código 4002, entre os anos 2007 a 2017 (em R\$ x1000)

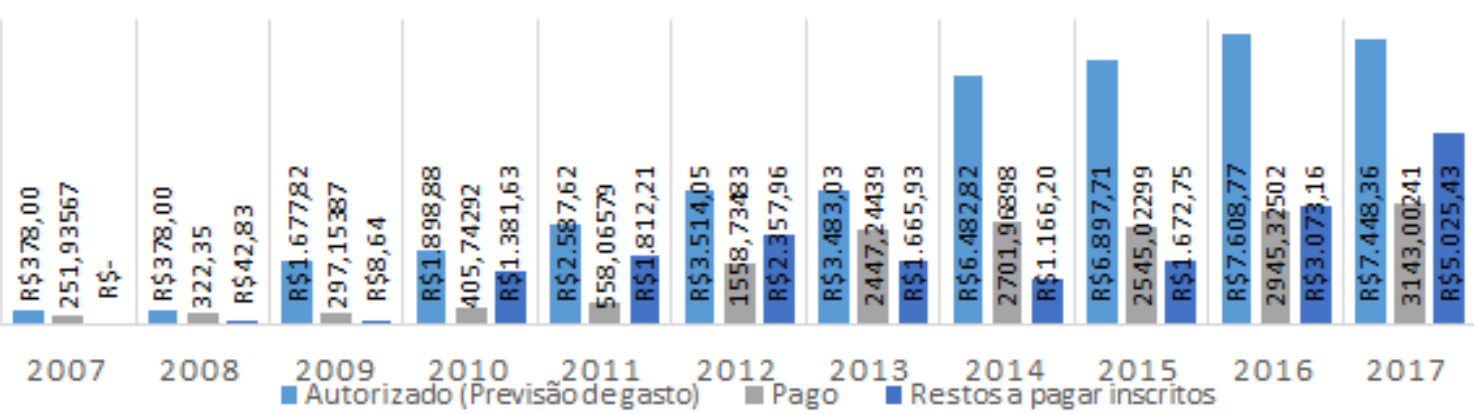

Fonte: Elaborada pelas autoras com base nos dados do Siafi Gerencial (2018)

RIAEE - Revista Ibero-Americana de Estudos em Educação, Araraquara, v. 16, n. 2, p. 508-523, abr./jun. 2021. e-ISSN: 1982-5587 
Para a consolidação da política de assistência estudantil na universidade, a instituição deve, mediante a autorização/previsão do orçamento do PNAES, alocar os recursos e empenhar conforme as áreas definidas pelo $\S 1^{\circ}$. do art. $3^{\circ}$ do Decreto $n^{\circ} 7.234 / 2010$. São elas: moradia estudantil, alimentação, transporte, atenção à saúde, inclusão digital, cultura, esporte, creche, apoio pedagógico e acesso, entre outros. Ao lado disso, a Portaria Normativa, em seu artigo $4^{\circ}$, define o público-alvo da assistência estudantil da seguinte forma:

Art. $4^{\circ}$ As ações do PNAES atenderão a estudantes matriculados em cursos presenciais de graduação, prioritariamente, selecionados por critérios socioeconômicos, sem prejuízo de demais requisitos fixados pelas instituições de educação superior em ato próprio (BRASIL, 2007).

Em outras palavras, entende-se que quaisquer estudantes poderão ser atendidos por meio das ações de assistência estudantil, sendo prioritário, todavia, o atendimento aos vulneráveis em termos socioeconômicos. Além disso, há de se destacar a possibilidade de a instituição estabelecer outros requisitos para esse processo de seleção.

Assim, ao levar em consideração as especificidades regionais e socioeconômicas da região a qual se localiza a UFGD e, somado a isso, diante da necessidade de garantir a permanência de seus estudantes, o Programa Bolsa Permanência da UFGD é destinado a custear a moradia, o transporte e os materiais escolares (aquisição de livros e cópias reprográficas, por exemplo) dos acadêmicos em condições econômicas vulneráveis. Diante desse contexto, a universidade optou por destinar cerca de $40 \%$ do total do recurso recebido pelo PNAES, conforme a Figura 2.

Figura 2 - Recursos empenhados e pagos no Programa Bolsa Permanência da UFGD, nos anos de 2014 a 2017 (em R\$ x1000)

—EMPENHADO

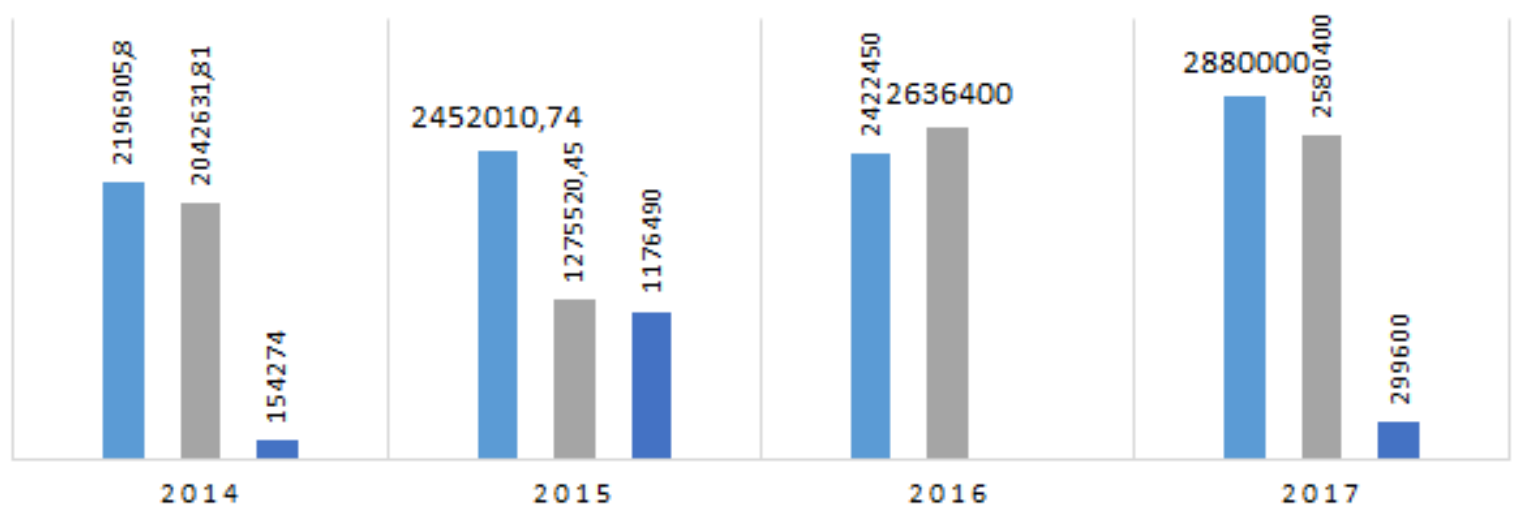

Fonte: Elaborada pelas autoras com base nos dados do Sistema Integrado de Planejamento e Orçamento (SIOP) (2018) 
$\mathrm{Na}$ figura acima, é possível perceber o quantitativo de recurso empenhado, pago e inscrito em restos a pagar. Por ser a avaliação do PNAES uma etapa final do processo, esta deve levar em conta as metas previstas conforme os objetivos e os recursos percebidos pela instituição de ensino superior.

No caso da instituição analisada, a UFGD, ao longo da pesquisa pôde-se constatar a inexistência de ferramentas capazes de fazer o monitoramento e a avaliação desses programas de assistência estudantil. Uma alternativa que trazemos, todavia, para sanar essa deficiência no ciclo da política educacional desenvolvida neste local é partir do levantamento desses números, tal como fizemos e projetamos na figura 2.

Compreendemos que é a partir desse levantamento feito pela instituição que se torna possível observar com maior clareza as ações que estão sendo desenvolvidas e se de fato estão conseguindo alcançar os objetivos propostos. Também é a partir desse monitoramento que se viabiliza examinar o quanto há de desperdício - ou não, em termos de valores monetários, em atividades malsucedidas. Aceito isso, depreende-se que tais valores, restantes de usos menos acertados, poderiam ser para programas e/ou ações, os quais atenderiam a outros tantos beneficiários e, assim, contribuiriam para uma maior eficiência da gestão.

Em virtude da autonomia prevista em lei para o uso de recursos pelas universidades, foi possível perceber durante o levantamento de dados por nós realizados em documentos oficiais tais como: (Relatórios de Gestão, Relatório de Auditoria, Relatório de Avaliação dos Resultados da Gestão, Atos Administrativos (Instruções de Serviços, Editais e Resoluções) e, principalmente, procurou-se respaldo na busca de Regulamentos próprios do Programa Bolsa Permanência da UFGD) da UFGD que esta instituição teve um aumento significativo no quantitativo de bolsas e valores a serem pagos aos alunos desde a implantação do programa até os dias de hoje. Tais bolsas buscaram atender às necessidades daqueles novos estudantes socioeconomicamente vulneráveis que ingressaram na UFGD no decorrer desse período. 
Figura 3 - Quantidade de bolsas previstas x quantidade de bolsas pagas

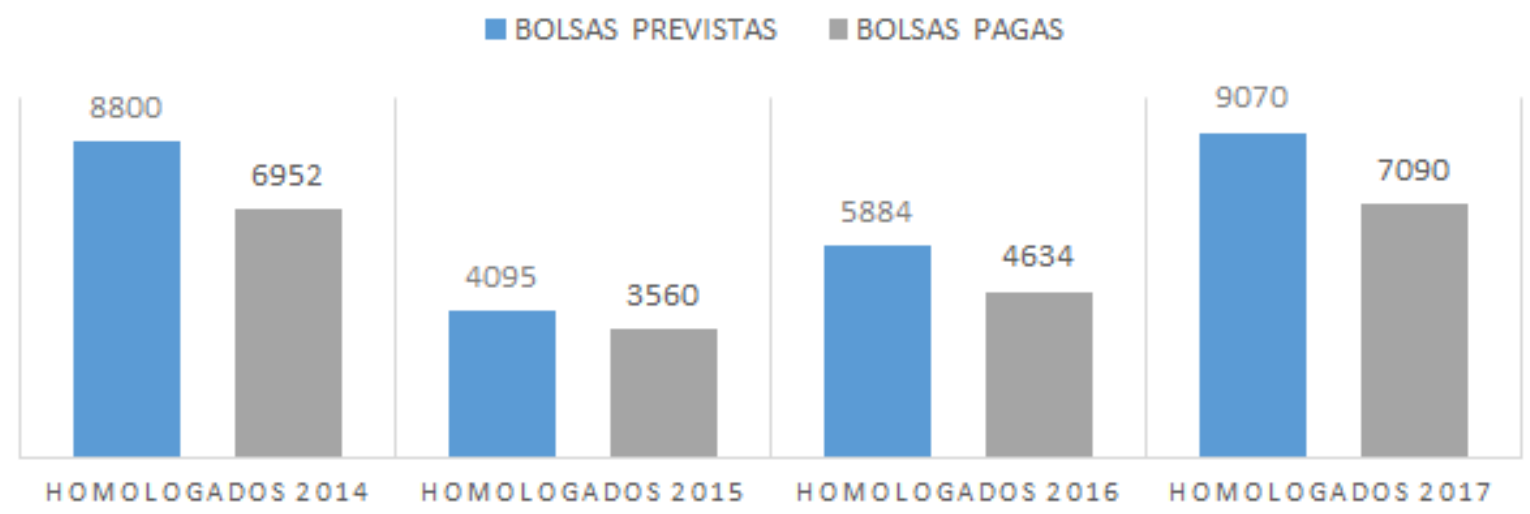

Fonte: Editais de divulgação PROAE (2018)

No ano de 2014, estavam previstas no edital de divulgação $\mathrm{n}^{\circ} 17$ o total de 8.800 bolsas. Tal processo teve a duração de dezesseis meses, com um total de duas chamadas. A quantidade de bolsas neste edital atingiu seu limite nos meses de agosto e outubro de 2013, quando foram pagas duas ou três bolsas de alunos que sofreram suspensão nos meses anteriores. Entretanto, nos demais pagamentos, perceberam-se sobras significativas de recursos e não houve estudos para o diagnóstico da causa.

No ano de 2015, devido à greve estabelecida nas IFES, o edital $n^{\circ} 45 / 2015$ foi lançado para os meses de novembro de 2015 a maio de 2016, com a previsão de 4.095 bolsas. Entretanto, foram homologados apenas 585 inscritos com expectativa de recebimento de bolsas e, desse total, já no primeiro mês teve uma baixa de quarenta e cinco bolsas. De modo incessante, nos meses seguintes, apenas aumentou o número do saldo de bolsas. Ao final, restaram 535 bolsas que não foram pagas aos estudantes com vulnerabilidade socioeconômica. Quanto à concentração da participação dos estudantes vulneráveis nos primeiros meses do processo, além do fato de um crescente aumento nos casos de suspensões e exclusões de bolsistas, o que pode ter sido provocado pela greve geral dos técnicos, há que se avaliar a explicação da sobra de bolsas nos demais anos, em que não houve o fato da greve e, ainda assim, persistiram elevados índices de exclusões.

Em 2016, foram lançados dois editais, sendo o primeiro o edital de $\mathrm{n}^{\mathrm{o}} 13 / 2016$, com previsão de 600 vagas, ou seja, 5.884 bolsas totais, e vigência de junho a dezembro de 2016, com prorrogação até fevereiro de 2017. O outro, o edital de no 30/2016, com vigência a partir de julho até dezembro do mesmo ano, previstas 72 vagas remanescentes, com o mesmo prazo de prorrogação. Percebe-se que essas vagas remanescentes seriam uma tentativa, já com expectativa de monitoramento, de reestruturar os saldos de bolsas que sobraram dos anos 
anteriores. Contudo, já no primeiro edital das 600 bolsas previstas foram homologadas 596 bolsistas e, no segundo edital, das 72 bolsas previstas, homologou-se 65 bolsistas. Percebe-se que neste edital há uma constante de pagamentos, sobretudo, nos meses de julho a dezembro, todavia, no mês de janeiro há uma queda significativa de pagamentos. Neste ano de 2016, os recursos destinados ao PNAES da UFGD pelo MEC foram de aproximadamente R\$10 milhões de reais. E, nessa perspectiva, apenas nos editais $n^{0} 13$ e 30/2016, a expectativa de sobra para com o Programa Bolsa Permanência da UFGD é de R \$ 500 mil reais. Constata-se que, apesar de uma insipiente ação de novas oportunidades de bolsas, há a necessidade de formas de monitoramento e avaliação do programa.

No ano seguinte, em 2017, o programa Bolsa Permanência da UFGD teve a estimativa de R 3.628.000,00 (três milhões seiscentos e vinte e oito mil reais) investidos em bolsas do Programa Bolsa Permanência UFGD, com uma estimativa de 9.070 bolsas nos editais $n^{\circ} 10$, 141 e 180 de 2017. No entanto, foram homologados nos três editais, apenas 1.039 bolsistas.

Por fim, a figura 3 representa não só o aumento da quantidade de bolsas previstas nos editais, como também o aumento do número de bolsas que não foram pagas. Essa sobra, se somadas ano a ano resultaria na quantidade de 5.713 bolsas e em quantidade de recurso desperdiçados na soma de 2.285.200,00 (dois milhões duzentos e oitenta e cinco mil e duzentos reais). Em resumo, o gerenciamento dos recursos públicos deve ser avaliado a todo momento pelos gestores, de forma a verificar se realmente foi necessário o destino da aplicação do recurso no Programa Bolsa Permanência da UFGD e, caso diagnosticada a falha, tal aplicação poderia ser redirecionada a outras ações, de forma que pudessem garantir a manutenção do estudante na universidade.

Isso porque, como já argumentado por Secchi (2010), no modelo conceitual de análise de política pública, ou ciclo de política pública, as fases de uma determinada política se misturam e se alternam, o que garante a avaliação, a qualquer momento, de determinada política, até mesmo durante a sua implementação.

\section{Considerações finais}

Com o presente trabalho foi possível verificar a relevância da Política de Assistência Estudantil na UFGD, no que tange à busca pela permanência dos graduandos. Mediante a expansão da Educação Superior, ocorrida a partir dos anos 2000, e a reserva de cotas para ingresso nas universidades, modificou-se o perfil dos estudantes, de forma a possibilitar o ingresso de alunos de classes socioeconômicas mais baixas, o que tornou essencial o 
fortalecimento das ações de assistência estudantil, com o propósito de minimizar as dificuldades dos graduandos em situação de vulnerabilidade socioeconômica.

Com isso, surge ao final do ano de 2007 o Programa Nacional de Assistência Estudantil (PNAES), com o objetivo de garantir a permanência do aluno na instituição, combater a evasão e a retenção, além de propiciar condições de igualdade. Logo, como uma política pública, fazem-se necessárias alternativas para o seu fortalecimento, o que consiste em avaliá-la sistematicamente e, por conseguinte, incide em um melhor planejamento e desenvolvimento das ações de assistência ao estudante desenvolvidas nas Universidades.

Portanto, o foco deste trabalho foi contextualizar o aporte financeiro concedido ao Programa de Assistência Estudantil na Universidade Federal da Grande Dourados (UFGD) e o panorama de utilização do recurso do Programa Bolsa Permanência da UFGD entre os anos de 2014 a 2017, o qual, nesse cenário institucional, demanda de grande recurso, advindo do PNAES, e é sujeito da garantia da permanência de muitos estudantes na UFGD, apontados em estudos (BRITO; COSTA; ALMEIDA, 2019).

Em relação aos objetivos desta pesquisa, primeiramente, discutiu-se sobre a Política Pública de Assistência Estudantil na Educação Superior. $\mathrm{Na}$ sequência, analisou-se o Programa Bolsa Permanência da UFGD sistematizado a partir do panorama do programa entre os anos de 2014 a 2017.

Em resumo, na análise dos dados coletados, observa-se que existe uma Política de Assistência Estudantil institucionalizada na UFGD, porém, há a inexistência de monitoramento e avaliação do programa, por parte de seus gestores. Mediante os resultados encontrados observou-se que devido a falta de acompanhamento há sobras de recursos, já empenhados e não utilizados em prol da permanência dos estudantes nos anos de 2015 e 2017. E que tais fatores podem ser atribuídos a falta de planejamento e estudo sistematizado das ações de assistência a serem oferecidas na instituição.

Por fim, acredita-se que o resultado desta pesquisa contribuirá para futuras pesquisas na instituição, de modo a tornar o debate da Política de Assistência Estudantil mais denso e consistente. Em relação ao Programa Bolsa Permanência da UFGD, sugere-se o estudo sobre os indicadores da concessão de bolsas e evasão.

\section{REFERÊNCIAS}

ANDRÉS, A. Aspectos da assistência estudantil, nas universidades públicas. Consultoria Legislativa, 2011. 
ARRETCHE, M. T. S. Tendências no estudo sobre avaliação. In: RICO. E. M. (Org.). Avaliação de políticas sociais: uma questão de debate. São Paulo: Cortez, 2009.

BRASIL. Constituição (1988). Constituição da República Federativa do Brasil. Brasília, DF: Senado, 1988.

BRASIL. Ministério da Educação. Portaria n. 39, de 12 de dezembro de 2007. Institui o Programa Nacional de Assistência Estudantil - PNAES. Brasília, DF, 13 dez. 2007.

Disponível em: http://portal.mec.gov.br/arquivos/pdf/portaria_pnaes.pdf. Acesso em: 10 out. 2020.

BRITO, A. C. T. C.; COSTA, A. K. T.; ALMEIDA, V. L. Gestão universitária: políticas comparadas de monitoramento do programa bolsa permanência em universidades federais brasileiras. Revista Ibero-Americana de Estudos em Educação, Araraquara, v. 14, n. esp. 3, p. 1862-1875, out. 2019. DOI: https://doi.org/10.21723/riaee.v14iesp.3.13036

CHAUÍ, M. Escritos sobre a universidade. São Paulo: Ed. UNESP, 2001.

CONDÉ, E. S. Abrindo a Caixa: dimensões e desafios na análise de Políticas Públicas.

FERNANDES, D. Pesquisas de percepções e práticas de avaliação no ensino universitário português. Estudos em Avaliação Educacional, São Paulo, v. 26, n. 63, p. 596-629, set./dez. 2015. DOI: https://doi.org/10.18222/eae.v26i63.3687

FINATTI, B. E.; ALVES, J. M.; SILVEIRA, R. J. Perfil sócio, econômico e cultural dos estudantes da Universidade Estadual de Londrina-UEL — indicadores para implantação de uma política de assistência estudantil. Libertas, Juiz de Fora, v. 6-7, n. 1-2, p. 246-264, jan./dez. 2007.

FONAPRACE. Revista Comemorativa 25 Anos: histórias, memórias e múltiplos olhares. Fórum Nacional de Pró-reitores de Assuntos Comunitários e Estudantis, ANDIFES - UFU, PROEX, 2012.

IMPERATORI, T. K. A trajetória da assistência estudantil na educação superior brasileira. Serviço social, São Paulo, n. 129, p. 285-303, maio/ago. 2017. DOI:

http://dx.doi.org/10.1590/0101-6628.109

Instituto Brasileiro de Geografia e Estatistica - IBGE. Síntese de indicadores sociais: uma análise das condições de vida da população brasileira. Coordenação de População e Indicadores Sociais. Rio de Janeiro: IBGE, 2015.

MACHADO, M. P. O pacto neodesenvolvimentista e as políticas de expansão da educação superior no Brasil de 2003 a 2013. Orientadora: Regina Maria Michelotto. 2013. 218 f. Tese (Doutorado em Educação) - Universidade Federal do Paraná, Curitiba, 2013.

MANCEBO, D.; VALE, A. A.; MARTINS, T. B. Políticas de expansão da educação superior no Brasil 1995-2000. Revista Brasileira de Educação, Rio de Janeiro, v. 20, n. 60, p. 31-50, jan./mar. 2015. DOI: https://doi.org/10.1590/S1413-24782015206003 
MARTINS, C. B. A Reforma Universitária de 1968 e a Abertura para o Ensino Superior Privado no Brasil. Educação e Sociedade, Campinas, v. 30, n. 106, p. 15-35, 2009. DOI: https://doi.org/10.1590/S0101-73302009000100002

RANIERI, N. B. S. O Estado democrático de direito e o sentido da exigência de preparo da pessoa para o exercício da cidadania, pela via da educação. 2009. Tese (Livredocência) - Faculdade de Direito, Universidade de São Paulo, São Paulo, 2009.

Revista Pesquisa e Debate em Educação, Juiz de Fora, v. 2, n. 2, 2013.

RIBEIRO, M. A. Projeto profissional familiar como determinante da evasão universitária: Um estudo preliminar. Revista Brasileira de Orientação Profissional, v. 6, n. 2, p. 55-70, 2005.

RISTOFF, D. Educação Superior no Brasil - 10 anos pós-LDB: da expansão à democratização. In: BITTAR, M.; OLIVEIRA, J. F.; MOROSINI, M. (Org.). Educação superior no Brasil - 10 anos pós-LDB. Brasília: INEP, 2008.

ROMANELli, O. O. História da Educação no Brasil. 34. ed. Petrópolis: Vozes, 2009.

SOUSA, L. M. Significados e sentidos das casas estudantis: um estudo com jovens universitários. Orientadora: Sônia Margarida Gomes Sousa. 2006. 112 f. Dissertação (Mestrado em Psicologia) — Universidade Católica de Goiás, Goiânia, 2006.

UFGD. Universidade Federal da Grande Dourados. Regulamento do Programa de assistência estudantil: Bolsa Permanência da UFGD. Dourados: UFGD, 2017.

\section{Como referenciar este artigo}

BRITO, A. C. T. C.; SOUZA, K. R.; ALMEIDA, V. L. Política pública de assistência estudantil no Ensino Superior: o Programa Bolsa Permanência na Universidade Federal da Grande Dourados. Revista Ibero-Americana de Estudos em Educação, Araraquara, v. 16, n. 2, p. 508-523, abr./jun. 2021. e-ISSN: 1982-5587. DOI: https://doi.org/10.21723/riaee.v16i2.13671

Submetido em: 09/05/2020

Revisões requeridas em: $13 / 08 / 2020$

Aprovado em: 30/10/2020

Publicado em: 01/02/2021 